\section{BMJ}

Open

Gastroenterology

\title{
Adult-onset autoimmune-type enteropathy: potential relationship to an adverse drug reaction
}

\author{
Runjan Chetty (D), Maria Cino, Allan Okrainec
}

To cite: Chetty R, Cino M, Okrainec A. Adult-onset autoimmune-type enteropathy: potential relationship to an adverse drug reaction. BMJ Open Gastro 2019;6:e000319. doi:10.1136/ bmjgast-2019-000319

Received 23 July 2019 Revised 2 0ctober 2019 Accepted 2 October 2019
Check for updates

(c) Author(s) (or their employer(s)) 2019. Re-use permitted under CC BY-NC. No commercial re-use. See rights and permissions. Published by BMJ.

University Health Network, Toronto, Ontario, Canada

Correspondence to Dr Runjan Chetty; runjan.chetty@gmail.com

\section{ABSTRACT}

Objective To describe an example of adult-onset autoimmune enteropathy (AIE) that coincided with druginduced reaction.

Design A 54-year-old patient was presented with Stevens-Johnson syndrome after a course of quinolones. This was followed shortly thereafter by epigastric pain, diarrhoea and weight loss. She also developed an autoimmune neutropenia.

Results Several biopsies were performed from the upper and lower gastrointestinal tract (GIT). The duodenal biopsies showed intraepithelial lymphocytosis; therefore, coeliac disease was considered. However, confirmatory serology was negative and the patient did not respond to a gluten-free/gliadin-free diet. Both upper and lower GIT biopsies consistently showed an absence of goblet cells resembling the changes of an AIE.

Conclusion This is an unusual case of autoimmunepattern enteropathy in an adult that was potentially druginduced.

Autoimmune enteropathy (AIE) is a recognised, although rare, disease caused by gut autoantibodies resulting in intractable diarrhoea. While it is typically seen in the paediatric age group, adult-onset has also been reported. ${ }^{1-3}$

In establishing criteria for AIE, Unsworth and Walker-Smith noted that patients needed to fulfil three criteria: (1) severe villous atrophy refractory to diet manipulation, (2) circulating gut autoantibodies and/or an autoimmune disorder and (3) absence of severe immunodeficiency. ${ }^{4}$

The role of drugs in causing gastrointestinal (GI) pathology is well-recognised. Drugs are thought to mediate diarrhoea via three main mechanisms: (1) accelerated motility, (2) mucosal inflammation or (3) enteropathy.

Histologically, the latter two features result in a picture very reminiscent of coeliac disease. Appropriate serological investigation for coeliac disease is negative and dietary restriction does not result in amelioration of symptomatology in these drug-induced enteropathies. ${ }^{5}$ Despite the severity of the inflammation and enteropathic changes induced by drugs, goblet cells are always present. Loss of goblet cells (with or without accompanying Paneth cell loss) is the hallmark histological feature of AIE.

We wish to highlight a unique case of autoimmune-type enteropathy in an adult where the onset of symptoms coincided with an adverse reaction to quinolones and was accompanied by autoimmune neutropenia.

\section{CLINICAL FEATURES}

In 2009, a 54-year-old woman was presented with fever, blistering facial skin rash and abdominal pain following administration of quinolones and a clinical diagnosis of Stevens-Johnson syndrome was made. Prior to this event, she did not report or complain of any GI symptoms. Following this acute episode of Stevens-Johnson syndrome, the patient continued to complain of difficulty swallowing and abdominal discomfort. An upper oesophagogastroduodenoscopy was undertaken in view of these symptoms. Brushings of the oesophagus showed candidiasis, and random biopsies of the stomach and duodenum showed chronic gastritis and features suggestive of coeliac disease, respectively. Investigation for coeliac disease showed the patient to be seronegative for coeliac disease antibodies. In addition, the patient did not respond to a gluten-free diet. Colonoscopy was found to be normal.

The patient's symptoms persisted with ongoing epigastric pain, diarrhoea and weight loss of $2-4 \mathrm{~kg}$ over a 3-4years period. During this period, the patient developed persistent neutropenia, which was deemed to be of autoimmune origin in view of the presence of antineutrophil antibodies. As a result of the persistence of symptoms, another upper endoscopy was done, revealing a polyp in the stomach that was diagnosed as an intramucosal carcinoma. The patient underwent 
a laparoscopic gastrectomy in 2011 for the intramucosal carcinoma, with an uneventful recovery.

Over the subsequent years, the patient developed sarcoidosis, and had persistent neutropenia with a normal bone marrow biopsy. She had intermittent dysphagia, as well as constipation alternating with diarrhoea and some symptoms of dumping. She underwent annual surveillance upper endoscopies for her history of gastric cancer. She was found to have oesophageal candidiasis on these annual upper endoscopies that was difficult to treat due to her history of allergy to the azole family of medications. The patient had several annual surveillance CT scans that did not reveal any significant bowel abnormalities. Her most recent abdominal CT in 2018, however, showed diffuse thickening of the colon with pericolonic stranding. A repeat colonoscopy performed 1 month after the CT revealed endoscopically normal-appearing mucosa from the rectum to cecum. Two sets of random biopsies revealed the pathological findings described in section Pathological findings and a final diagnosis of AIE was made.

The patient was prescribed loperamide on a p.r.n. (pro re nata) basis together with dietary exclusion of dairy products and gluten and has shown some improvement in her symptoms.

\section{PATHOLOGICAL FINDINGS}

The biopsy findings from 2011 revealed Helicobacter pylorinegative, acute on chronic gastritis (figure 1A). The duodenum biopsies displayed flattening of the surface mucosa with subtotal attenuation of villi, increase in intraepithelial lymphocytes with increased acute and chronic inflammation in the lamina propria (figure 1B). Occasional apoptotic figures were noted in the crypts.

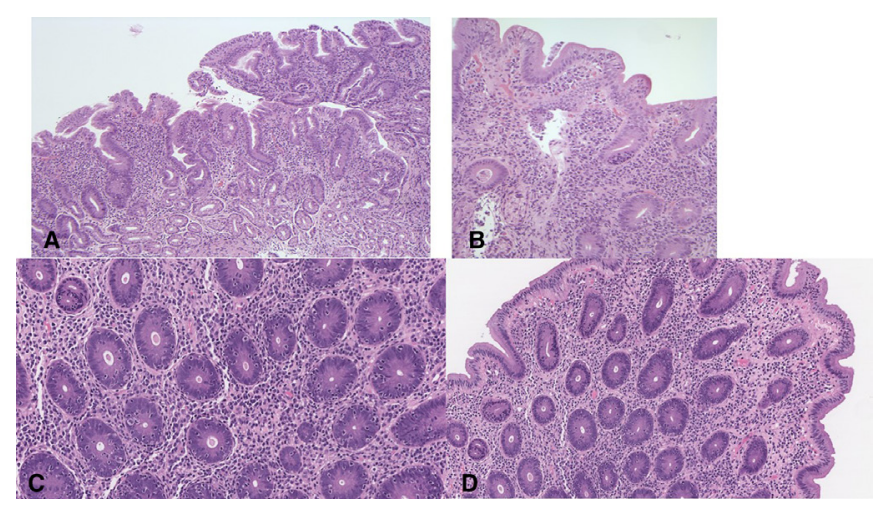

Figure 1 (A) Gastric antrum biopsy showing moderate chronic gastritis with numerous plasma cells in the lamina propria and occasional intraepithelial lymphocytes in the surface mucosa and glands. (B) The duodenum biopsy shows subtotal villous atrophy with flattening, increase in intraepithelial lymphocytes and plasma cells within the lamina propria. Note the absence of goblet cells in the biopsy. (C) A colon biopsy showing an appreciable increase in intraepithelial lymphocytes especially within glands. (D) The striking feature is the complete absence of goblet cells in both the surface mucosa and within glands.
At that time, a diagnosis of coeliac disease was rendered. However, on review, there was a striking absence of goblet cells and Paneth cells.

The 2018 set of colon biopsies showed a mild increase in surface intraepithelial and crypt lymphocytosis (figure 1C). Apoptosis and acute cryptitis were also seen. A striking feature, once again, was the complete absence of goblet cells in all biopsies (figure 1D).

All histological changes were completely in keeping with the findings encountered in AIE.

\section{DISCUSSION}

AIE is a rare disease typified by intractable diarrhoea and histological evidence of villous atrophy in the small intestine, accompanied by the presence of autoantibodies. These patients do not respond to diet manipulation and usually require treatment with immunosuppressives. ${ }^{1-4}$ Although AIE is most prevalent in infants within the first 6 months of life, cases have been documented in adults. ${ }^{1-3}$

Drugs can cause a myriad of changes in the GI tract but in particular, ACE inhibitors, such as olmesartan, can induce an enteropathy ('olmesartan-associated enteropathy') with histological changes resembling coeliac disease. In addition, mycophenolate mofetil (an antirejection drug used post-transplantation) can result in villous atrophy of the duodenum. To the best of our knowledge, there has only been one report linking a drug to AIE. ${ }^{6}$ Greenson contends that some adult patients with AIE have a history of olmesartan ingestion despite also having antienterocyte antibodies. ${ }^{6}$ He further suggested that olmesartan could have acted as a trigger for the AIE. ${ }^{6}$

In the various published series of adult-onset AIE described thus far, a drug history has not been highlighted or implicated as potentially causative of AIE. In the case under discussion, the patient's GI symptomatology coincided with the Stevens-Johnson like reaction to quinolones and the patient simultaneously developed an autoimmune neutropenia. A common causative link could be a drug-induced aetiology given the two somewhat disparate entities. Both AIE and autoimmune neutropenia, although typically encountered in childhood, can occur in adults without childhood disease or an antecedent precipitating cause. However, the coexistence of two childhood unconnected autoimmune diseases in an adult is more than likely due to a common precipitating cause and in this case, the link is an adverse reaction to quinolones.

The histopathological changes encountered in this patient have consistently shown an absence of goblet cells, which is the most typical feature of AIE. Besides olmesartan, it would appear that no other drug has been associated with lack of goblet cells. We describe a case of an adult manifesting enteropathic clinical features with histopathological features of AIE and a concomitant autoimmune neutropenia with antineutrophil antibodies. Although antigoblet cell and antienterocyte antibodies were not sought in this patient, the presence of such 
antibodies are not required when the histopathological changes are so characteristic, if not pathognomonic. ${ }^{7}$

Contributors $\mathrm{RC}, \mathrm{MC}$ and $\mathrm{AO}$ all contributed equally to the planning, conduct and reporting of the work described in the article. $\mathrm{RC}$ is responsible for the overall content as guarantor.

Funding The authors have not declared a specific grant for this research from any funding agency in the public, commercial or not-for-profit sectors.

Competing interests None declared.

Patient consent for publication Obtained.

Provenance and peer review Not commissioned; externally peer reviewed.

Data availability statement There are no data in this work. No data are available.

Open access This is an open access article distributed in accordance with the Creative Commons Attribution Non Commercial (CC BY-NC 4.0) license, which permits others to distribute, remix, adapt, build upon this work non-commercially, and license their derivative works on different terms, provided the original work is properly cited, appropriate credit is given, any changes made indicated, and the use is non-commercial. See: http://creativecommons.org/licenses/by-nc/4.0/.
ORCID iD

Runjan Chetty http://orcid.org/0000-0002-2124-515X

\section{REFERENCES}

1. Corazza GR, Biagi F, Volta U, et al. Autoimmune enteropathy and villous atrophy in adults. Lancet 1997;350:106-9.

2. Daum S, Sahin E, Jansen A, et al. Adult autoimmune enteropathy treated successfully with tacrolimus. Digestion 2003;68:86-90.

3. Akram S, Murray JA, Pardi DS, et al. Adult autoimmune enteropathy: Mayo clinic Rochester experience. Clin Gastroenterol Hepatol 2007;5:1282-90.

4. Unsworth DJ, Walker-Smith JA. Autoimmunity in diarrhoeal disease. $J$ Pediatr Gastroenterol Nutr 1985;4:375-80.

5. Marietta EV, Cartee A, Rishi A, et al. Drug-Induced enteropathy. Dig Dis 2015;33:215-20

6. Greenson JK. The biopsy pathology of non-coeliac enteropathy. Histopathology 2015;66:29-36.

7. Gentile NM, Murray JA, Pardi DS. Autoimmune enteropathy: a review and update of clinical management. Curr Gastroenterol Rep 2012;14:380-5. 